\title{
Detecting Value Co-Creation Emergence to Foster Innovation
}

\author{
Aurelio Tommasetti, Massimiliano Vesci, Mara Grimaldi, Antonella Monda \\ Department of Business Science, Management \& Innovation Systems, University of Salerno, Fisciano, Italy \\ Email: rettore@unisa.it, mvesci@unisa.it,margrimaldi@unisa.it, anmonda@unisa.it
}

How to cite this paper: Tommasetti, A., Vesci, M., Grimaldi, M. and Monda, A. (2019) Detecting Value Co-Creation Emergence to Foster Innovation. Journal of Service Science and Management, 12, 17-33. https://doi.org/10.4236/jssm.2019.121002

Received: September 29, 2018

Accepted: January 1, 2019

Published: January 4, 2019

Copyright $\odot 2019$ by authors and Scientific Research Publishing Inc. This work is licensed under the Creative Commons Attribution International License (CC BY 4.0).

http://creativecommons.org/licenses/by/4.0/ Open Access

\begin{abstract}
Purpose: The work analyzes the concept of emergence according to ecosystems view. Therefore, the study proposes an integrated framework based on the combination of Viable Systems Approach (VSA) and Service-Dominant logic (S-D logic). The concept of service ecosystems and the identification of their main elements allows at pinpointing the main drivers for value co-creation and innovation that can lead to co-evolution as the key driver to challenge complexity. However, co-evolution is an unintelligible construct that can be observed only in the ongoing processes of value co-creation emergence. Methodology/Approach: Starting from the identification of the common points and of the dissimilarities between S-D logic and VSA, a matching between viable systems and service ecosystems is proposed to reveal the key drivers leading to the emergence of viable value co-creation. Then, the main elements of viable systems and ecosystems are integrated and subdivided into three drivers (value propositions, resource integration, institutions) for viable value co-creation and co-evolution in (eco)systems organizations. Findings: The integration between viable systems and ecosystems permits to reread emergence, intended as a key driver to challenge complexity in VSA, according to ecosystems perspective by leveraging on the notion of value co-creation as an ongoing process that can foster co-evolution over time. In this way, the concept of systems emergence can be reinterpreted in the light of value co-creation notion and based on a viable ecosystems view that can contribute to reveal the main drivers (resource integration, institutions and value propositions) and outcome (innovation and co-evolution) of value co-creation emergence. Implications: From a theoretical point of view, the study enhances a better understanding of emergence by associating the construct (relatively unexplored in literature) with value co-creation by shedding light on the mechanisms underlying service interactions. Regarding managerial standpoint, revealing the drivers to detect the emergence of viable value co-crea-
\end{abstract}


tion can aid managers to elaborate strategies for managing the unexpected and optimizing relationships among actors in order to challenge complexity. Originality/Value: By reinterpreting the concept of emergence according to ecosystems perspective, the work proposes an innovative application of the process of systems emergence to value co-creation mechanisms and rereads innovation as co-evolution, intended as a dynamic output of emergence. The viable ecosystems view on emergence and the identification of its drivers can advance a research agenda for further research aimed at analyzing: 1) the main strategies to challenge complexity; 2) the antecedents and drivers of co-creation; 3 ) the relationship between value co-creation and innovation.

\section{Keywords}

Emergence, Viable Systems Approach, Service-Dominant Logic, Service Ecosystems, Value Co-Creation

\section{Introduction}

Current markets are characterized by mounting environmental complexity that leads organizations to adopt dynamic and flexible layouts based on the redefinition of traditional value exchanges and of the asymmetric relationships between consumers and providers to embrace a systems and networked view grounded on collaboration among users.

In service era, the fast pace of technological change and the constant evolution in user's needs reveal the necessity to reframe businesses processes [1] [2] to manage the emergence of value co-creation and foster the creation of new value, service and innovation.

Starting from the analysis of these shifts in the definition of service, product and value, Service-dominant logic (S-D logic) [3] [4] [5] is one of the most relevant services theories that conceptualizes markets as networks of co-creating actors [6] [7]. The cornerstone of the theory is value co-creation, the joint production of value among users, providers and all the actors engaged in service provision. To stress the systems nature of value exchange and of resource integration, in its recent developments, the framework advances the notion of service ecosystems [8] [9] [10].

Over the course of time, the need to study the appearance of value co-creation with the aim to understand and challenge complexity emerges. Value co-creation can be reinterpreted in line with the category of dynamism and turbulence and with the aim of co-evolution [9].

If value co-creation creates innovation over time, then studying co-creation allows at understanding and managing innovation. Thus, the study of co-creation emergence can give birth to a better understanding of co-evolution processes. 
For this reason, by providing new interpretative schemes for challenging complexity [11], the meta-model proposed by Viable systems Approach (VSA) [12] [13] can be considered as a suitable theory for the analysis of emergence in value co-creation. VSA adopts a broadened organizational perspective by shifting the attention from user's standpoint (at an interactive level) to the exploration of overall system's dynamics [14] [15].

Therefore, the aim of the work is to apply the notion of emergence (as conceptualized in VSA in terms of systems emergence) to value co-creation (S-D logic) understanding. Then, by understanding innovation as output of value co-creation [16], co-evolution can be reframed as an output of emergence. Thus, the integration between the two theories allows at rereading emergence with reference to a better management of value co-creation that can generate innovation and co-evolution over time.

Ecosystems, as sects of actors, interactions and resources exchange, are considered as the most suitable layouts enabling value co-creation emergence. The concept of service ecosystems and the identification of their main elements allows at pinpointing the main drivers for value co-creation and innovation that can lead to co-evolution as the key driver to challenge complexity. However, co-evolution is an unintelligible construct that can be observed only in the ongoing processes of value co-creation emergence. For this reason, ecosystems should be reread according to viable systems approach that provides the right management schemes to challenge complexity.

By conceptualizing viable ecosystems, the connection between value co-creation emergence and innovation is highlighted [17] and it is hypothesized the existence of a link between institutions, resource integration and innovation [16].

Therefore, the work combines VSA and service ecosystems view toward a better understanding of emergence in line with a system view on value co-creation and innovation. The study aims at observing and conceptualizing emergence according to a value-based perspective that identifies: 1) the key factors fostering value co-creation and innovation; 2) the potential shift from value co-creation systems emergence and co-evolution. The study seeks to answer the following research question:

RQ: Is it possible to combine Service ecosystems view with Viable System Approach to reread value co-creation concept through the notion of systems emergence?

The goal of the paper is pursued through the integration of ecosystems viewin line with the last developments in S-D logic-that identifies the multiple relationships among actors in service exchanges with VSA that can offer a wider organizational perspective framing these interactions. The last theory shifts from a micro-level of analysis (that describes the elements of the ecosystem) to a meta-level that explores how the different ecosystem's actors and resources can be managed in a systems view [14] [15]. Thus, a theoretical rereading of the no- 
tion of emergence (VSA) in the light of the analysis of the dynamics underlying the appearance of value co-creation and innovation (S-D logic) is performed through a literature review (paragraph 2). Then, a model is proposed to identify the main factors that decision-makers should optimize to challenge emergence (and, thus complexity) by managing strategically value co-creation and turning environmental turbulence into innovation opportunities.

The article is structured as follows: in the theoretical section, the key assumptions of VSA (paragraph 2.1) and S-D logic (paragraph 2.2) are introduced and discussed in order to propose a reframing of emergence to reinterpret value co-creation (and the potential innovation deriving from it) as an emergent phenomenon. In Section 3, some potential drivers and outcomes, antecedents and consequences of value co-creation practices that aim at being innovation-oriented are advanced.

The proposition of an integrated framework rereading ecosystems and its main elements through viable systems approach can help to detect the main drivers for value co-creation and innovation. Revealing these drivers can contribute to the advancement of contemporary service research, since the main drivers for value co-creation and innovation have been explored until now [16] [18].

\section{Theoretical Background. Viable Systems and Service Ecosystems}

Starting from a brief overview on VSA main dichotomies and on service ecosystems view (S-D logic), a dimensioning of the key features of both theories is proposed. In this way, the concept of emergence is explored with reference to systems emergence (VSA), firstly, and is related with the concept of value co-creation and ecosystems reformation (S-D logic), then. Therefore, the main antecedents for co-creation and innovation are introduced (thanks to ecosystems view) and a combined framework rereading innovation emergence through value co-creation according to VSA main assumptions is advanced.

\subsection{Viable systems Approach (VSA): Main Assumptions}

Viable systems approach (VSA) [12] [13] stands out from among contemporary service and management theories for the proposition of a systems mind-set for understanding markets and enveloping the issues related to service delivery in order to advance a general perspective addressing managers to survive in complex contexts. Differently from service theories such as Service-dominant logic [3] [4] or Service logic [19], VSA does not focus on service exchanges (at a micro-interactive level) but it proposes a meta-model providing new interpretative schemes to reread organizations as systems [11]. By analysing systems' ability to renew over time [20], VSA aims at identifying the mechanisms fostering knowledge exchange to gain competitive advantage and ensure co-evolution in the long run. 
Thanks to a systems and strategic approach, the theory seems to be suitable for a better understanding on how decision makers can promote viability by challenging complexity and fostering innovation and co-evolution.

The core philosophy of VSA is based on dichotomies. The main opposition is structure-system dichotomy [21]. The entire organization (and viable systems composed of systems embedded with each other's) is based on dual layout made of: 1) an operating structure (structural dimension); 2) a set of interconnections between supra-components and sub-components supervised by a governing body to achieve common goals [22] [23].

Therefore, the duality is the cornerstone of VSA, the theoretical foundation of its philosophy that synthesizes reality by understanding systems synergy as a higher level and meta-construct that tries to challenge complexity through the constant mediation between static and dynamic, abstract and concrete levels to attain the final system's goal (viability).

As Figure 1 shows, the concept of synthesis represents the mind-set of the whole theory that aims at overcoming the focus on one of the side of the figure. The two sides (structure or system; consonance or resonance) are not opposite but should be synthesized.

Dichotomy is not viewed as an opposition, but rather it provides the possibility of an integration, of a meta-model that observes structural component, first, and systemic result, then, to integrate the two dimensions and define reality. The theory (rather than simply shifting the attention from the parts to the whole) adopts a viewpoint synthesizing between reductionism and holism and analyses both: 1) parts and their relationship; 2) the whole [24] [25].

In line with this dual level of analysis, the isotropy postulate [13] states that each organization owns a structure, which can be transformed into a system by concretely activating relationships with sub-systems and supra-systems [25].

Structure is intended as an operating set of components and individuals having the ability to perform specific functions, activities and tasks by complying with (legal, economic, institutional) rules and constraints. System arises from the dynamic expression of structure that is the structure in action that operates under the supervision of the governing body. It can be considered as a picture of the structure during the real interactions among its components.

Thus, as a general meta-philosophy, VSA proposes a systems-transcending view to understand better reality by mediating between structure and system and managing constantly the emergence of synergy across the two levels, as depicted in Figure 2.

\section{From Consonance to Resonance: Toward Emergence}

Therefore, as debated above, the dichotomy structure-system can be associated with the dichotomy consonance-resonance.The passage from structural consonance to systemic resonance requires a transition from a static to a dynamic level. In the first dimension, components are just potentially linked based on structural compatibility. It is only through the system that the activation of real 


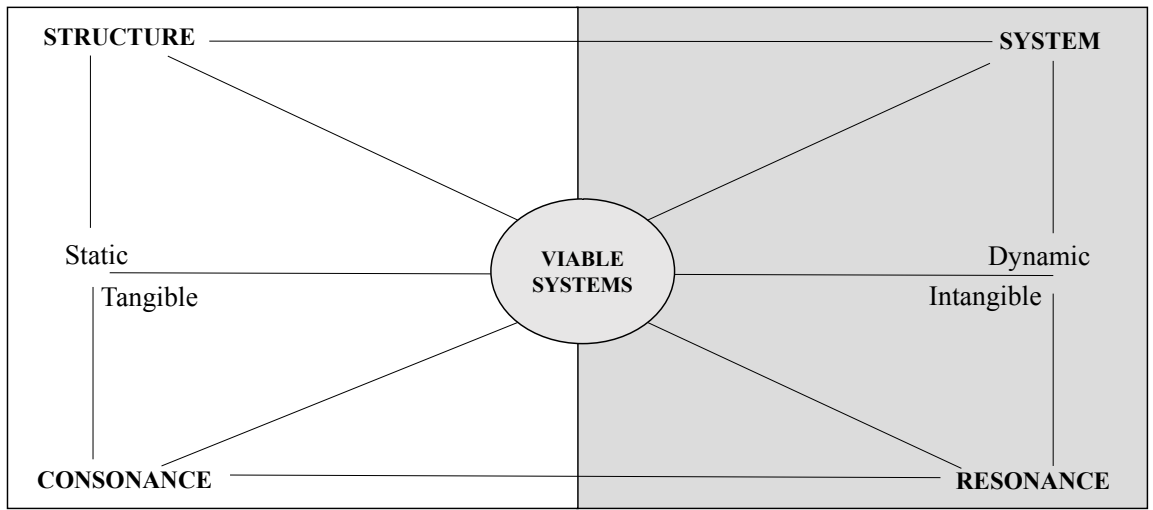

Figure 1. VSA main dichotomies: a synthesis approach. Source: author's elaboration.

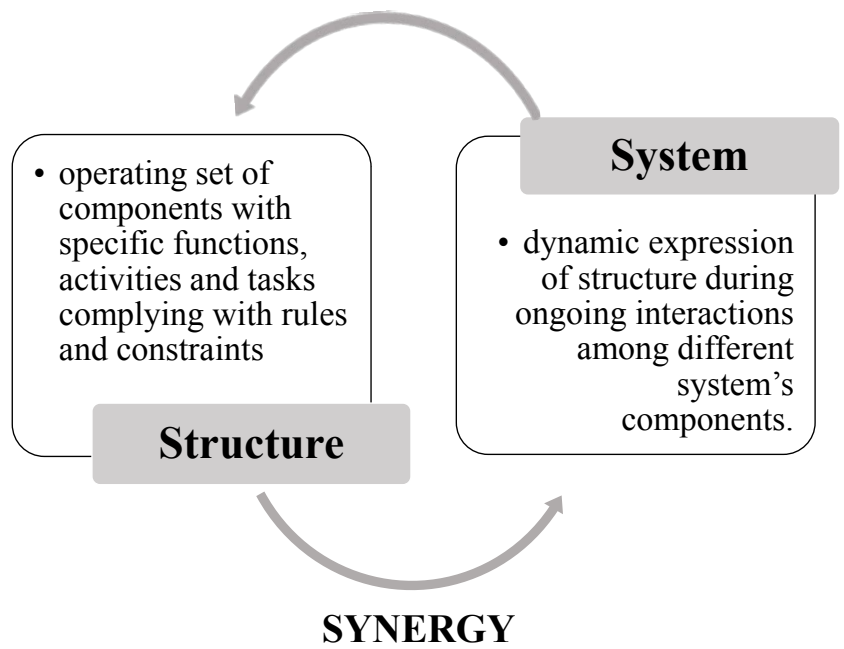

Figure 2. From structure to system and beyond. Source: author's elaboration.

interaction "in context" can give birth to synergistic outcome.

Thus, by combining all the dichotomies and trying to synthesize them, viable systems should search for two simultaneous conditions, strictly related to structure-system and static-dynamic dimensions: consonance is the potential structural compatibility among systems members at a static level, which should be turned into resonance, the dynamic level of real harmonious interactions that fosters system's emersion [26].

These two levels help to manage relationships with stakeholders and above all to develop them over time and to generate co-evolution.

The final outcome of viable systems, that can be acquired mediating between consonance and resonance, is viability, that is the capacity of surviving over time [20] and to acquire sustainable competitive advantage in turbulent scenarios through dynamic adaptations of relationships (at structure and system level) and constant transformation of organizational design, business restructuring and rethinking (see Figure 3).

Therefore, since the concept of emergence can be placed at a "high" level of description (more theoretical), it needs to be explored according to a tran- 


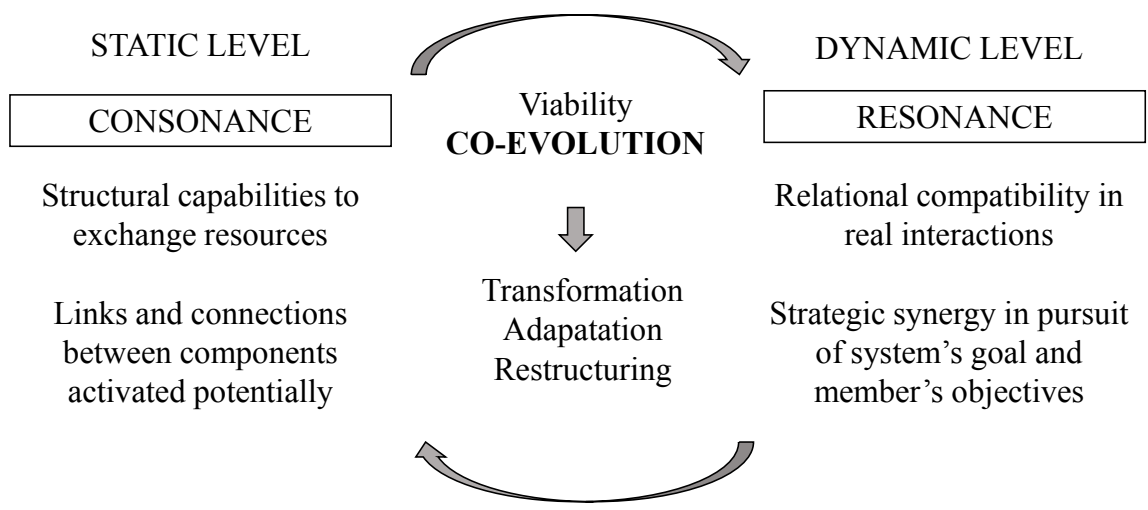

Figure 3. Beyond the dichotomies: a synthesis view. Source: author's elaboration.

scending perspective [27] [28] in line with VSA's general mind-set and with the last all for research introduced in S-D logic [29].

As Figure 4 shows, it can be hypothesized that system emerges from the structure in a governed but also uncontrolled way. Even with the constant monitoring and regulation of interactions accomplished by decision makers (planned dimension), there will be always a part of interaction that can be considered as "emergent" (unplanned dimension, see Figure 4). Thus, not all the organizational processes are completely governable. For instance, management can select the proper stakeholders to establish resonant relationships based on the presupposition of consonance between the given ecosystem and these partners. However, during the real interactions (value-in-use) [4] the resources, skills and experience provided by actors cannot be predicted a priori and can give birth to successful resource exchange (value co-creation) but also to ineffective value co-creation (co-destruction). It follows that the identification of the "portion" devoted to the emergence of (negative or positive) unforeseen phenomena and to the "palce" of effective value co-creation can help managers to understand how relational and co-creation strategies can be organized and optimized throughout the entire ecosystem and to prevent potential co-destruction behaviours and not only to react to them. The aim is to turn the unpredictable emergence of problems into business opportunities: for instance, the provision of user's personal negative experience and complaints on a service can be transformed into insights to improve the service and enhance new service development. Thus, according to the prevention of the "alea" underlying value co-creation, management can acquire the possibility to develop innovation.

For this reason, the concept of emergence requires special attention, since it contributes to identify the organizational "alea" (complexity) and to detect the "unmanageable". Emergence is defined as a process strictly dependent on the observer and on the context in which it verifies that generates new systems elements from the interactions and combinations of pre-existing components and in which new entities are generated. 


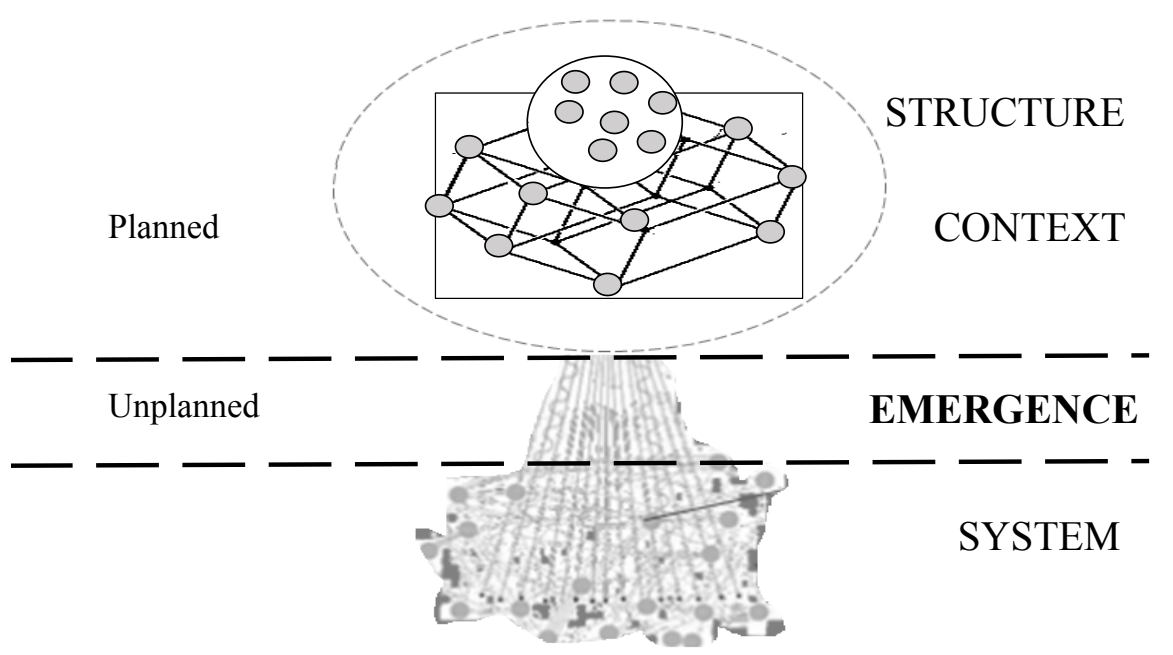

Figure 4. Emergence in VSA. Source: author's elaboration.

\subsection{S-D logic and Service Ecosystems: Key Concepts}

Starting from the paradigm shift to a service-oriented economy proposed in services marketing literature [30] [31], Service-dominant logic (S-D logic) [3] [4] [8] reframes the role of users in service exchanges as active participants (actor-to-actor, A2A) and resource integrators in the final determination of value. Therefore, the notion of value co-creation stands out as the emblem of S-D logic defining the detachment from the distinction between producers and consumer to reinterpret each user as co-creator.

Introduced by Prahalad and Ramaswamy [32], the concept of value co-creation is the symbol of a broader shift in services and relationship marketing that proposes a service-oriented logic to redefine the traditional meaning of interactions in service exchanges [33] [34]. Several years later, in 2004, the analysis of value co-creation is recovered within S-D logic that makes it as the emblem of the whole theory and as a key concept that helps to conceptualize the overcoming of the traditional logic of exchange, Good Dominant-logic (G-D logic) [3], towards the service-dominant logic proposal.

The alternative point of view proposed by Vargo and Lusch proposes the transition (from the logic of added value) towards the centrality of the collaborative view on economic transactions that exalts consumers as active participants in the process, rather than as passive "receivers" of service.

Thus, the object of the exchange in contemporary service era changes and it is focused no longer on tangible dimensions but on knowledge and immaterial capacities, whose value consequently needs to be co-produced with users. The desirable outcome of the process of value exchange is not anymore merely an economic utility but the sharing of tangible assets and resources that can increase the well-being of all the members in a system.

According to Vargo and Lusch [4], services are based on the application of knowledge and skills and are the basis of every exchange that gives life to mutual benefits between individuals. Thus, the provider-consumer relationship also 
changes. The latter is always a co-producer and the provider is to be considered only as a supplier of a given "value proposition". In this relational-oriented view, it follows that value is not determined a priori by producers but is co-created in a collaborative way with each stakeholder involved in the process. The final co-created value is the result of a continuous mediation among actors in which each becomes a "co-creator" and resource integrator (actor-to-actor view, A2A).

Based on an all-embracing perspective of organizations as network of relationships, actors and value, Vargo and Akaka [35] introduce service ecosystems by broadening the concept of service [36] [37]. The ecosystem view fosters the adoption of a systems view for understanding the drivers and the dynamics of exchange [38] and for emphasizing at the same time the role of social links in value creation.

According to Vargo and Lusch ([39] p.176), service ecosystems are "relatively self-contained, self-adjusting system[s] of resource-integrating actors connected by shared institutional logics and mutual value creation through service exchange".

The concept of ecosystems highlights the complex nature of service exchanges as multiple process of resource integration among a set of heterogeneous actors interacting with each other to achieve shared goals [8].

According to the different definitions of service ecosystems proposed in literature, the main elements of these networked entities can be identified: 1) institutions, (i.e. rules, norms, meanings) regulating exchanges based on common social rules and shared practices that act as prerequisites for resource integration; 2) resource integration that occurs during real interactions but also before and after delivery; 3 ) value propositions, as a set of common values which lead users to pursue shared purposes [40].

The dynamic combination of these elements can lead to the establishment of dynamic co-evolution paths enhancing the attainment of sustainable competitive advantage based on the continuous renewal of value and production of new knowledge at an ecosystem level. Sincere resource integration and value co-creation occur throughout service ecosystems, the constant regeneration and enrichment of value after the multiple resource exchanges over time can produce new solutions (i.e., innovation) to new and existing problems. In this way, ecosystems and the value propositions that rule them become (re)institutionalized and markets continue to form and reform [29].

\section{Integrating VSA and S-D Logic: Emergence in Viable Ecosystems}

The main commonalities between service ecosystems and viable systems stress the potential complementarity between S-D logic and VSA. S-D logic can provide VSA with clarifications on the main drivers of value co-creation and innovation, whereas VSA managerial focus can allow at shedding light on how managers can develop strategies aimed at increasing competitiveness. 
In this way, the rereading of value co-creation (S-D logic) according to a systems and strategic perspective (VSA) can help to shed light on the managerial implications and the strategic management of value co-creation. Therefore, the combination of S-D logic and VSA can contribute to address a gap arisen from literature and related to the absence of research on the strategic management of value co-creation [41] and also innovation [42]. The integrated approach (S-D logic VSA) helps to (re)conceptualize the processes and practices foundational to value creation and innovation, including market formation and reformation.

The abstract and context-based features of systems emergence can be associated with ecosystems view that seems to redefine all the main elements of viable systems in terms of value.

Thus, the main dimensions of viable systems (structure-system and consonance-resonance) can be reread according to (or supported by) the ecosystem's main elements identified above (institutions, resource integration, value proposition) and their renewal over time (restructuring) to understand better the phenomenon of emergence.

Therefore, the following propositions (synthesized in Figure 5 and derived from a combination of VSA's main assumptions and the key variables, actors and processes of ecosystems) can be advanced:

1) The transformation of structure into system (VSA) in viable (eco)systems can be enabled through the alignment between stakeholder's finalities and overall system's goal. The harmonization of the two different kind of objectives can be pursued through the establishment of effective (micro) value propositions (S-d logic) that can be internalized within the entire ecosystem and turned into (macro) shared intention (S-D logic);

2) The matching between goals and finalities can arise from the transition of structure into system and of consonant interactions into resonant relationships. Therefore, resonant relationships (VSA) can be reread as the outcome of effective resource integrating process (S-D logic);

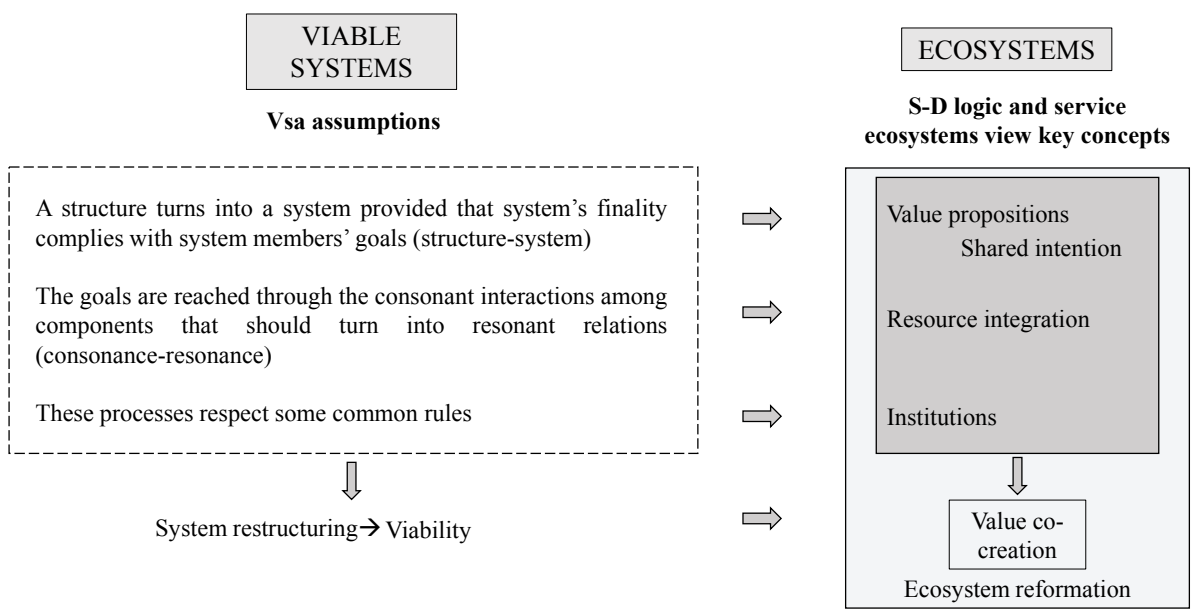

Figure 5. Viable systems and ecosystems: matching of their key dimensions. Source: author's elaboration. 
3) The rules that govern interaction can be reframed as institutions;

4) The core concept of restructuring in VSA, that is the driver for viability, can be associated with ecosystems reformation.

In the latest contributions from S-D logic, resource integration, value propositions and the ongoing interactions among multiple stakeholders give birth to market reformation that is the emergence and institutionalization of new solutions [43]. Therefore institutionalization and emergence can be associated and viability can be intended as the outcome of value co-creation.

By pursuing common goals, resonant resource integration increases and value co-creation is fostered generating viability thanks to constant reformation and reshaping of value over time.

The integration between viable systems and ecosystems and between the two concepts of emergence and ecosystems reformation can highlight directions for future research.

If value co-creation can produce innovation, then an adequate exploration of value co-creation allows at understanding and managing innovation appearance. Therefore, the study of co-creation emergence (value co-creation occurring during systems emergence) can give birth to a better understanding of co-evolution.

As Figure 6 shows, value co-creation can be observed according to the dichotomy planned-unplanned:

1) planned dimension: value co-creation produces innovation through actor's engagement and resource integration;

2) unplanned dimension: innovation (output of co-creation) can become co-evolution (output of emergence) through continuous emergence of unplanned value co-creation.

In a circular and recursive process, rethinking the relationship between systems elements and their adaptation to markets can shed light on how innovation and institutionalization arise from the ingoing emergence and maintenance of new solutions.

In this way, emergence can be interpreted as the creative product deriving from the dynamic combination of value propositions exchange and resource integrating processes that can foster innovation

Emergence gives birth to transformation and social change: therefore, it is not a simple and predictable sum of individual contributions but it is the active outcome of resource integrating processes that create new resources, including structures, which are not reducible to component resources and combinatorial rules [27] [28].

In particular, as depicted in Figure 7, the entities generated can be: 1) new resources and new resource integrating practices; 2) new interaction modalities in context; 3) new social practices and institutions that turn into new values and competencies.

The constant emergent reformation gives birth to the establishment of new value generated (institutionalization) in the long run by realizing co-evolution and, thus, viability. 


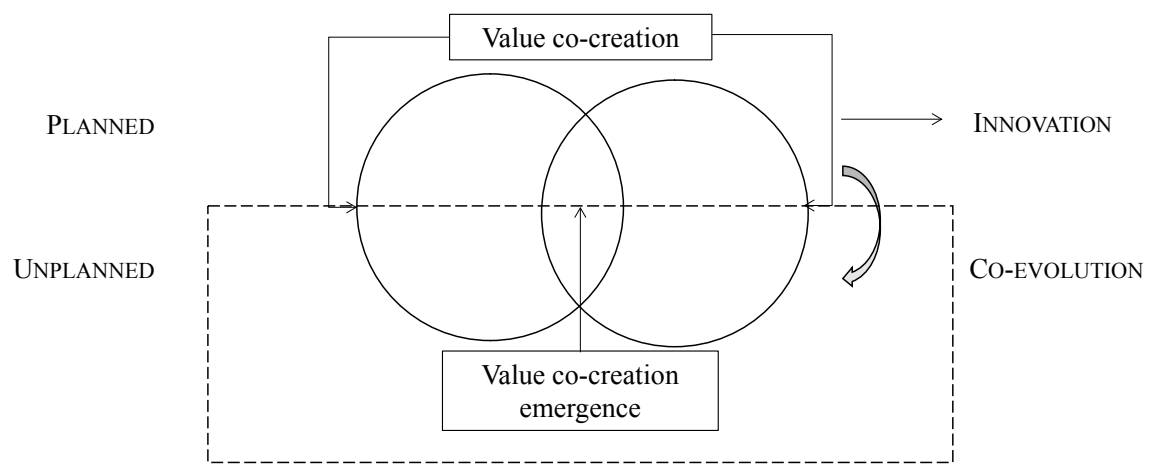

Figure 6. Planned and unplanned dimension in ecosystems. Source: author's elaboration.

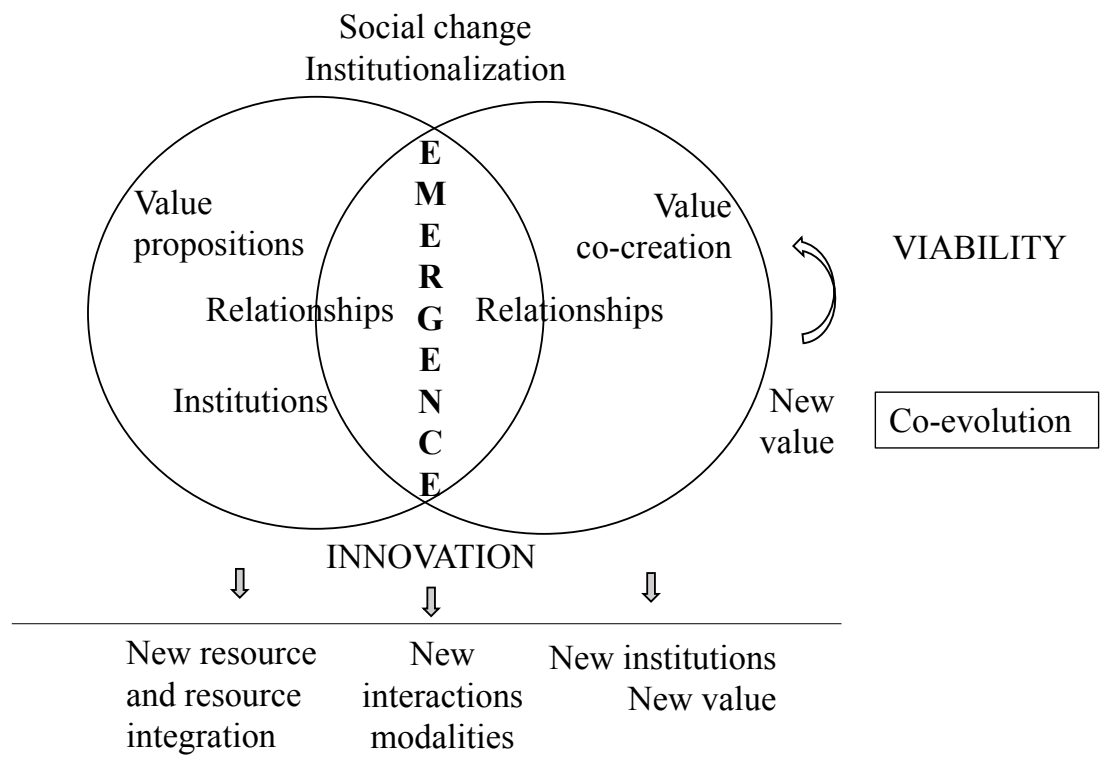

Figure 7. Emergence in viable ecosystems. Source: author's elaboration.

The combination of ecosystems dimensions in order to reread emergence processes can encourage exploring further how creativity co-creation arising from given interactions (in the systems emergence) can give birth to innovation, co-evolution and viability over time.

\section{Discussion}

A systems view on value co-creation emergence deriving from the integration of VSA and S-D logic can address future research to (re)conceptualize the processes and practices that are foundational to value creation and innovation, including market formation and reformation. Moreover, some theoretical advancements in service research can concern a better exploration of the different co-creation antecedents, activities and practices that can influence service improvement and innovation. In this way, managers can be encouraged to rethink business models and combine dynamically the resources exchanged by incorporating co-creation into organizational strategies and by including innovation-oriented mind-set in the elaboration of value propositions. 
By merging the micro-interactive level (S-D logic) with the meta-perspective of VSA, the study addresses future research to the adoption of a "meta" perspective that moves back to the analysis of the antecedents of value co-creation and to its outcome. The integrated model permits to identify: 1) the main drivers of value co-creation; 2) the mechanisms leading to value emergence and knowledge renewal through the continuous production of innovation.

The main contribution of the framework is the proposition of a meta-approach for managers that aims at overcoming complexity and instability in contemporary hypercompetitive markets. By understanding how value co-creation can be boosted and turned into innovation, decision-makers can understand better the underlying dynamics that can give birth to emergence and to management "alea". In this way, by ruling the unpredictable nestled in value co-creation, the resources exchanged by users (skills, experience, positive and negative comments on the service) can be transformed into new knowledge that can increase information variety and can challenge complexity. Proactive managers can learn how to seize opportunities from the resource exchanged within the ecosystem and can understand how potential co-destruction behaviours can be prevented. To manage the "unmanageable" section of service exchanges and value co-creation can contribute to pinpoint the most adequate strategies to foster effective value co-creation and to turn the unpredictable emergence of problems into business opportunities.

\section{Conclusions}

The study proposes a research agenda for further research related to the necessity of elaborating a strategic framework defining the different value co-creation practices [18]. This systems mind-set is in line with the call for research from Storbacka et al. [16] on the need to explore the multiple resources integration occurring among multiple actors in contemporary ecosystems and with the call from Barile et al. (2016) to employ a transcending perspective to explore ecosystems.

The work stresses the relevance of knowledge and interactive dimensions as drivers of value co-creation but also the importance of contextual dimensions (culture, institutions, values, etc.). Human component seems to be relevant since the continuous enhancement of actor's engagement can renew knowledge through the constant and real time exchange between users across pre-delivery and post-delivery.

From a managerial viewpoint, the proposition of some drivers for viable value co-creation (Resource integration, institutions, relationship management, etc.) can help decision-makers to develop useful co-creation strategies in each phase of service delivery. What is more, the combined model proposed can shed light on the potential strategic steps fostering innovation and value co-creation management, by contributing to address the gap in literature related to the absence of studies exploring value co-creation from a managerial standpoint. 
Therefore, the framework addresses managers to better understand: 1) how inputs and outcomes of emergence can foster value co-creation and innovation; 2) how outputs (new value) can act as a basis for the constant renewal of values that leads to innovation and co-evolution over time.

Additionally, the work can aid managers to understand how to manage relationships with actors and how to encourage and enhance their engagement by optimizing knowledge exchanges and information flows. Therefore, decision-makers can monitor value co-creation and innovation in progress during all the phases of service provision by supervising the emersion of co-creation in real time and increasing engagement at each stage. Then, by understanding innovation as an output of value co-creation (Storbacka et al., 2016), co-evolution can be reframed as a long-time and reiterated consequence of an effective management of emergence.

However, the work represents a conceptual contribution providing theoretical advancements that can represent the starting point to elaborate a systems and strategic perspective on value co-creation emergence. The study can be intended as the first step to identify the drivers of co-creation and innovation that can be explored through following contributions. Future research can start from the assumptions proposed in this study and from the main propositions of viable (eco)systems view to detect empirically the main drivers of value co-creation and innovation through qualitative (case studies, interviews, observation, focus groups, etc.) or quantitative analysis (statistical correlation between social dimensions, resource integration, value co-creation, innovation, etc.).

\section{Conflicts of Interest}

The authors declare no conflicts of interest regarding the publication of this paper.

\section{References}

[1] Chesbrough, H. and Spohrer, J. (2006) A Research Manifesto for Services Science. Communications of the ACM, 49, 35-40. https://doi.org/10.1145/1139922.1139945

[2] Chesbrough, H. (2007). Business Model Innovation: It's Not Just about Technology Anymore. Strategy \& Leadership, 35, 12-17. https://doi.org/10.1108/10878570710833714

[3] Vargo, S. L. and Lusch, R.F. (2004) Evolving to a New Dominant Logic for Marketing. Journal of Marketing, 68, 1-17. https://doi.org/10.1509/jmkg.68.1.1.24036

[4] Vargo, S.L. and Lusch, R.F. (2008) Service-Dominant Logic: Continuing the Evolution. Journal of the Academy of Marketing Science, 36, 1-10. https://doi.org/10.1007/s11747-007-0069-6

[5] Vargo, S.L. and Lusch, R.F. (2010) From Repeat Patronage to Value Co-Creation in Service Ecosystems: A Transcending Conceptualization of Relationship. Journal of Business Market Management, 4, 169-179.

https://doi.org/10.1007/s12087-010-0046-0 
[6] Gummesson, E. (2002) Relationship Marketing in the New Economy. Journal of Relationship Marketing, 1, 37-57. https://doi.org/10.1300/J366v01n01_04

[7] Grönroos, C. (2008) Service Logic Revisited: Who Creates Value? And Who Co-Creates? European Business Review, 20, 298-314. https://doi.org/10.1108/09555340810886585

[8] Vargo, S.L. and Lusch, R. F. (2016). Institutions and Axioms: An Extension and Update of Service-Dominant Logic. Journal of the Academy of Marketing Science, 44, 5-23. https://doi.org/10.1007/s11747-015-0456-3

[9] Vargo, S.L., Koskela-Huotari, K., Baron, S., Edvardsson, B., Reynoso, J. and Colurcio, M. (2017) A Systems Perspective on Markets-Toward a Research Agenda. Journal of Business Research, 79, 260-268. https://doi.org/10.1016/j.jbusres.2017.03.011

[10] Vargo, S.L., Wieland, H. and Akaka, M.A. (2015) Innovation through Institutionalization: A Service Ecosystems Perspective. Industrial Marketing Management, 44, 63-72. https://doi.org/10.1016/j.indmarman.2014.10.008

[11] Barile, S. and Polese, F. (2010) Linking the Viable System and Many-to-Many Network Approaches to Service-Dominant Logic and Service Science. International Journal of Quality and Service Science, 2, 23-42. https://doi.org/10.1108/17566691011026586

[12] Barile, S. (2000) Contributi Sul Pensiero Sistemico in Economia d'Impresa. Centro Studi di Tecniche Aziendali, Arnia, WM Stampa Editoriale srl, Atripalda, Italy.

[13] Golinelli, G.M. (2000) L'approccio Sistemico al Governo dell'Impresa. L'Impresa Sistema Vitale, Cedam, Padova

[14] Barile, S., Pels, J., Polese, F. and Saviano, M. (2012) An Introduction to the Viable Systems Approach and Its Contribution to Marketing. Journal of Business Marketing and Management, 2, 54-78.

[15] Pels, J., Polese, F. and Brodie, R.J. (2012) Value Co-Creation: Using a Viable Systems Approach to Draw Implications from Organizational Theories. Mercati $e$ Competitività, 1, 19-38.

[16] Storbacka, K., Brodie, R.J., Böhmann, T., Maglio, P.P. and Nenonen, S. (2016) Actor Engagement as a Microfoundation for Value Co-Creation. Journal of Business Research, 69, 3008-3017. https://doi.org/10.1016/j.jbusres.2016.02.034

[17] Lusch, R.F. and Nambisan, S. (2015) Service Innovation: A Service-Dominant Logic Perspective. MIS Quarterly, 39, 155-175. https://doi.org/10.25300/MISQ/2015/39.1.07

[18] Saarijärvi, H., Kannan, P.K. and Kuusela, H. (2013) Value Co-Creation: Theoretical Approaches and Practical Implications. European Business Review, 25, 6-19. https://doi.org/10.1108/09555341311287718

[19] Grönroos, C. and Voima, P. (2013) Critical Service Logic: Making Sense of Value Creation and Co-Creation. Journal of the Academy of Marketing Science, 41, 133150. https://doi.org/10.1007/s11747-012-0308-3

[20] Barile, S. and Saviano, M. (2011) Foundations of Systems Thinking: The Structure-System Paradigm. In: Contributions to Theoretical and Practical Advances in Management. A Viable Systems Approach, International Printing, Avellino, 1-24.

[21] Barile S. (2008) L'impresa come sistema. Contributi sull'Approccio Sistemico Vitale (ASV). Giappichelli, Torino.

[22] Polese, F. and Di Nauta, P. (2013) A Viable Systems Approach to Relationship Management in S-D Logic and Service Science. Die Betriebswirtschaft, 73, 113-129.

[23] Golinelli, G.M. and Gatti, M. (2001) The Firm as a Viable System. Symphonya. 
Emerging Issues in Management, No. 2, 38-63. https://doi.org/10.4468/2001.2.04golinelli.gatti

[24] Von Bertalanffy, L. (1968) General System Theory. George Braziller, New York.

[25] Golinelli, G.M., Gatti, M. and Vagnani, G. (2002) Dalla struttura al sistema: Elementi per una riflessione sui confini, i rapporti con la proprietà, la flessibilità e l'elasticità dell'impresa. In: Golinelli, G.M., Ed., L'approccio sistemico al governo dell impresa, Vol. 3, Cedam, Padova.

[26] Barile, S. and Polese, F. (2010) Smart Service Systems and Viable Service Systems: Applying Systems Theory to Service Science. Service Science, 2, 21-40. https://doi.org/10.1287/serv.2.1_2.21

[27] Peters, L. (2014) Emergent vs. Summative Resource Integration and Value Co-Creation in Service-Ecosystems. UBS Research Paper Series No. 2014-07.

[28] Peters, L.D. (2016) Heteropathic versus Homopathic Resource Integration and Value Co-Creation in Service Ecosystems. Journal of Business Research, 69, 2999 3007. https://doi.org/10.1016/j.jbusres.2016.02.033

[29] Vargo, S.L., Wieland, H. and Akaka, M.A. (2016) Innovation in Service Ecosystems. Journal of Serviceology, 1, 1-5.

[30] Grönroos, C. (2000) Relationship Marketing: The Nordic School Perspective. In: Sheth, J.N. and Parvatiyar, A., Eds., Handbook of Relationship Marketing, Vol. 1, SAGE, Thousand Oaks, 95-117. https://doi.org/10.4135/9781452231310.n4

[31] Gummesson, E. (2004) Return on Relationships (ROR): The Value of Relationship Marketing and CRM in Business-to-Business Contexts. Journal of Business \& Industrial Marketing, 19, 136-148. https://doi.org/10.1108/08858620410524016

[32] Prahalad, C.K. and Ramaswamy, V. (2002) The Co-Creation Connection. Strategy and Business, 27, 50-61.

[33] Gummesson, E. (1994) Broadening and Specifying Relationship Marketing. AsiaAustralia Marketing Journal, 2, 31-43. https://doi.org/10.1016/S1320-1646(94)70276-8

[34] Grönroos, C. (1996) Relationship Marketing Logic. Asia-Australia Marketing Journal, 4, 7-18. https://doi.org/10.1016/S1320-1646(96)70264-2

[35] Vargo, S.L. and Akaka, M.A. (2012) Value Cocreation and Service Systems (Re) Formation: A Service Ecosystems View. Service Science, 4, 207-217. https://doi.org/10.1287/serv.1120.0019

[36] Maglio, P.P. and Spohrer, J. (2008) Fundamentals of Service Science. Journal of the Academy of Marketing Science, 36, 18-20. https://doi.org/10.1007/s11747-007-0058-9

[37] Vargo, S.L., Maglio, P.P. and Akaka, M.A. (2008) On Value and Value Co-Creation: A Service Systems and Service Logic Perspective. European Management Journal, 26, 145-152. https://doi.org/10.1016/j.emj.2008.04.003

[38] Chandler, J.D. and Vargo, S.L. (2011) Contextualization and Value-in-Context: How Context Frames Exchange. Marketing Theory, 11, 35-49. https://doi.org/10.1177/1470593110393713

[39] Vargo, S.L. and Lusch, R.F. (2011) Reducing the Fear of Crime in a Community: A Logic of Systems \& System of Logics Perspective. Proceedings of the Grand Challenge in Service Week. Understanding Complex Service Systems through Different Lens, Cambridge, 2011, 1-25.

[40] Akaka, M.A., Vargo, S.L. and Lusch, R.F. (2013) The Complexity of Context: A Service Ecosystems Approach for International Marketing. Journal of International 
Marketing, 21, 1-20.

[41] Barile, S., Lusch, R., Reynoso, J., Saviano, M. and Spohrer, J. (2016) Systems, Networks, and Ecosystems in Service Research. Journal of Service Management, 27, 652-674. https://doi.org/10.1108/JOSM-09-2015-0268

[42] Nambisan, S., Lyytinen, K., Majchrzak, A. and Song, M. (2017) Digital Innovation Management: Reinventing Innovation Management Research in a Digital World. MIS Quarterly, 41, 223-238. https://doi.org/10.25300/MISQ/2017/41:1.03

[43] Lusch, R.F., Vargo, S.L. and Gustafsson, A. (2016) Fostering a Trans-Disciplinary Perspectives of Service Ecosystems. Journal of Business Research, 69, 2957-2963. https://doi.org/10.1016/j.jbusres.2016.02.028 